
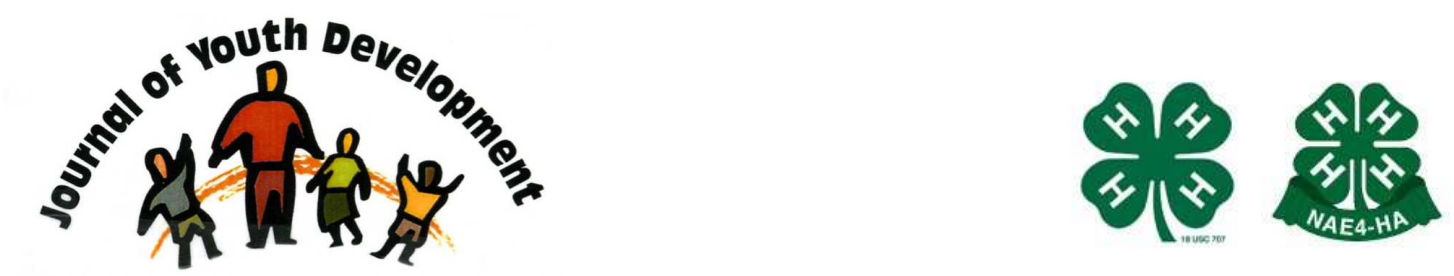

Bridging Research \& Practice

\title{
Training Staff to Create Caring Communities: Promises and Challenges
}

\author{
Laurie P. Browne \\ California State University, Chico \\ Chico, CA \\ Ipbrowne@csuchico.edu
}

Jim Sibthorp

University of Utah 


\title{
JOURNAL OF YOUTH DEVELOPMENT \\ bridging research and practice

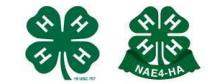

Volume 9, Number 4, Winter 2014

Article 140904FA003

\section{Training Staff to Create Caring Communities: Promises and Challenges}

\author{
Laurie P. Browne \\ California State University, Chico \\ Jim Sibthorp \\ University of Utah
}

\begin{abstract}
Caring communities support the healthy growth of young people by fostering caring youth-staff relationships as well as a sense of connectedness to the people and norms within that setting. Out-of-school-time (OST) programs may be uniquely situated to serve as caring communities, particularly if staff are trained to facilitate caring activities and employ an ethic of care when interacting with youth. These processes can also be described as program design and staff implementation. Program design, which refers to the structured aspects of a program, differs from implementation, or the ways staff interacts with youth throughout the program, because design factors are typically robust to differences in individual staff members' style. Implementation, on the other hand, varies with respect to the individual staff member. The purpose of this study was to examine the effects of a two-part staff training intervention focusing on program design and staff implementation on youths' sense of caring community. Findings from this study and their implications for managers of OST programs are discussed.
\end{abstract}

\section{Introduction}

Caring communities support the healthy growth of young people through caring one-on-one relationships as well as through connectedness to the people and norms that characterize the setting in general. Through caring and connectedness, caring communities are critical contexts for positive youth development. In the school setting, for example, fourth grade students who felt cared for by their teachers reported lower trait anxiety, anger, and higher coping skills than their peers who did not feel cared for by a particular teacher (Rice, Kang, Weaver, \& Howell, 
2008). Connectedness to the school setting as a whole similarly contributes to desirable outcomes such as improved mental (Shochet, Dadds, Ham, \& Montague, 2006), behavioral (McNeely, \& Falci, 2004; Resnick, Bearman, Blum, et al., 1997), and academic (Catalano, Haggerty, Oesterle, Fleming, \& Hawkins, 2004) health. Given the breadth of evidence linking caring and connectedness to positive youth outcomes, it is not surprising that caring communities are considered protective environments (Resnick, et al., 1997).

Like the school setting, out-of-school-time (OST) programs offer opportunities for youth to experience a caring community. Youth-staff relationships are a particularly important characteristic in these settings because youth often form meaningful relationships with OST program staff (Rhodes, 2004). Summer day camps are OST programs that offer unique relationship-building opportunities and, as such, are considered contexts for positive youth development (Garst, Browne, \& Bialeschki, 2011). Summer camps are particularly known for positive youth-staff and youth-peer relationships (Bialeschki, Henderson, \& James, 2007; Thurber, Scanlin, Scheuler, \& Henderson, 2007), which suggest they are ideal contexts for youth to experience a caring community. Peer relationships in OST programs are not always positive, though, as documented in Moore's $(2002,2001)$ examination of processes related to race and gender discrimination among youth in day camps. Furthermore, staff in OST programs typically encounter unexpected situations and dilemmas that may inhibit the development of positive relationships (Halpern, Barker, \& Mollard, 2000; Larson, Rickman, Gibbons, \& Walker, 2009). Given the importance yet somewhat variable nature of youth-peer and youth-staff relationships in OST programs, it is critical that staff are trained specifically to foster a sense of caring community. Therefore, the purpose of this study was to examine the effects of a twopart staff training focused on program design and staff implementation on youths' sense of caring community within an OST program.

\section{Training Staff to Foster Caring Communities}

Training staff to foster a sense of caring community can include two primary components:

a) providing staff an intentionally designed program and training them to use it, and

b) training staff to engage an ethic of care when they interact with youth at the point of service.

Program design represents aspects of the program that are intentionally planned in order to reach a desired outcome (Roark, Gillard, Evans, Wells, \& Blauer, 2012). As extensions of a program's goals, design features should remain consistent over time. Staff implementation, on the other hand, represents the ways individual staff members deliver structured activities. Because these factors depend on individual characteristics, implementation generally varies in relation to staff member skills, attitudes, and personalities (Ewert, \& Sibthorp, 2014). Implementation factors can also include "artistic features" of a program, such as program themes and overall climate (Ellis, \& Rossman, 2008). Together, design and implementation factors represent two ways OST staff can promote a sense of a caring community. These mechanisms and their conceptual underpinnings are discussed below.

\section{Program Design}

Intentionally designed activities are an example of a program design factor known to promote desired outcomes in youth programs (Roark, et al., 2012). Effective OST programs prioritize structured, purposeful activities over unstructured time (Roth, \& Brooks-Gunn, 2003), perhaps because they are generally robust to individual staff members' styles and day-to-day fluctuations in the program (Ewert, \& Sibthorp, 2014). Training staff to effectively facilitate 
activities intentionally designed to promote caring is one way an OST program might promote a caring community. This approach may be especially promising when training young and inexperienced OST staff. In their investigation OST program staff, Halpern and colleagues (2000) found that inexperienced staff members struggled adapting to unexpected changes in the program, leading them to conclude that program design factors, such as structured activities, provided much needed support to inexperienced staff members.

One example of an intentionally designed program is the Caring School Communities (CSC; Battistich, Solomon, Watson, \& Schaps, 1997) curriculum. CSC classroom, whole-school, and community-based activities are designed to foster caring community through student-teacher relationships, student-student relationships, and within the school as a whole (Battistich, et al., 1997). Researchers have demonstrated positive effects of the CSC in the school setting, including student outcomes such as social skills and overall connectedness to school (Battistich, Schaps, \& Wilson, 2004). Furthermore, the CSC appears to be relatively robust to staff implementation (Domitrovich, \& Greenberg, 2000). The CSC curriculum provides a promising framework for training staff to facilitate structured activities designed to promote a sense of caring community.

\section{Staff Implementation}

Despite the robust nature of activities like the CSC, design factors in general depend on staff members' implementation styles. OST program staff interact closely with youth during structured and unstructured time and each individual staff member brings personal attributes that characterize the ways they connect to program participants. Implementation factors refer to the qualities of a program that depend on the individual staff member, such as social norms, organizational climate (Eccles, \& Gootman, 2002), and other "artistic factors" (Ellis, \& Rossman, 2008). Smith, Devaney, Akiva, and Sugar (2009) describe the ways individual staff members interact with youth at the point of service. The effects of training teachers (Tarlow, 1996), mentors (Rhodes, 2004), and athletic coaches (Newton, Watson, Gano-Overway, Fry, Kim, \& Magyar, 2007) to promote caring community is well documented; however, effective methods for training youth workers in general are less clear (Shek, \& Wai, 2008).

One approach to training staff to foster caring communities focuses on helping staff to engage an ethic of care when interacting with youth at the point of service. Noddings (2003) describes an ethic of care as a bidirectional exchange between a care-giver and one in-need that starts unequal (the one in-need relies on the care giver in some way) but, through the caring exchange, both parties in time benefit equally. The point of service, or the point at which youth interact with program staff (Smith, et al., 2010), is where youth might experience a staff member's ethic of care. Larson and colleagues (2009) contend that staff training should focus on the expertise staff need at the point of service because, when staff are trained to engage personal reasoning, they are better able to connect meaningfully with youth while navigating unexpected situations within the program. To create a caring community, then, staff must be trained how to employ an ethic of care when they interact with youth at the point of service.

Given these intertwined approaches to training staff to foster a caring community, two specific research questions informed this study:

a) Will a two-part staff training session that focuses both on program design and staff implementation increase youths' sense of caring community more so an OST program without this staff training? and 
b) Will a combination of trainings specific to program design and implementation factors affect youths' sense of their OST program as a caring community more so than either training in isolation?

\section{Methods}

This study employed a mixed methods design to answer the research questions. Quantitative data were collected from campers via a self-report questionnaire at three different times during the program in order to examine the within-and between-subjects effects of the staff training sessions. Qualitative data were gathered from program staff at the end of the program.

\section{Setting and Participants}

Twelve male $(N=7)$ and female $(N=5)$ program staff members between the ages of 21 and 33 ( $M_{\text {age }}=26$ years) participated in this study, eight of whom attended both staff training sessions. Half of the counselors $(N=6)$ had worked at the study site for two to three years, two were in their first year, and four had worked on site for four or more years. With respect to level of educational attainment, half $(N=6)$ of the staff members indicated they were currently working towards an undergraduate degree, four had already earned a bachelor's degree, and one had completed a master's degree.

Youth at three different sites of a summer day camp completed the research questionnaires. Program fees varied depending on household income ( $\$ 10 /$ month to $\$ 400 /$ month), with most families paying roughly $\$ 200$ for each of the two available 4-week sessions. While enrollment varied from session to session, each site served between 45 and 60 youth per session; approximately $75 \%$ of whom attended both 4-week sessions. Each site maintained a 1 to 10 staff to participant ratio for a total of four to seven staff members on site each day. The overarching goal of the program was to promote positive youth development through a variety of skill-building activities. Daily activities included arts and technology, drama, sports, cooking, and outdoor adventures; field trips, guest performers, and special themed events rounded out the session. Participants were divided into age groupings (e.g., 9 and 10 year olds, 11 and 12 year olds) for certain activities each day but most activities integrated participants of all ages. Ages ranged from 7 to 14 years old.

\section{Measurement}

To measure the multidimensional nature of caring community, the concept was defined to include caring (youths' one-on-one connections with program staff) and connectedness (youths' connections to their peers and norms of the program in general). Independent measures of caring and connectedness were combined to form a single paper and pencil self-report instrument completed at three different times during the summer. Caring was measured with the Caring Climate Scale (Newton, Fry, Watson, Gano-Overway, Kim, \& Magyar, 2009) which considers two facets of caring: (a) youth-adult interactions and (b) youths' interactions with the group as a whole. This scale, which was developed for use in a youth sport program, is based largely on Noddings's (2003) concept of caring and includes 14 items to which participants respond using a five-point Likert-type rating scale ( $1=$ strongly disagree to $5=$ strongly agree). Items asked respondents to reflect specifically on program staff ("The leaders are kind to $\mathrm{me}^{\prime \prime}$ ) as well as on the group as a whole ("Everyone likes one another for who they are"). This scale has demonstrated evidence of internal structure $(a=.92)$ and content validity among 9 - to 17 year-old participants in the youth sport setting (Newton, et al., 2009). 
Connectedness was measured using the Camp Connectedness Scale from the American Camp Association's Youth Outcomes Battery (ACA, 2011). This scale assesses youths' overall relationship with the people and norms within the setting in general. In the camp context, this scale has demonstrated sound psychometric properties among 8 - to 12-year-olds $(a=.87)$. The scale is largely based on Libbey's (2004) work on school connectedness and includes six domains: belonging, discipline and fairness, likes camp, youth voice, peer relations, safety, and staff support. Sample items included "I like the other kids" and "I feel like I belong."

Respondents completed each of the 12 items by responding to a five-point Likert-type rating scale $(1=$ strong disagree to $5=$ strongly agree $)$.

Qualitative data were gathered through staff interviews. The site coordinators and select program staff from each of the three sites were interviewed following the intervention periods. The researcher posed open-ended questions designed to elicit reflection on the intervention and the features of the program session that may have impacted the goals of the training. Each interview lasted approximately one hour and was recorded and transcribed by one of the authors.

\section{Procedures}

Two staff training sessions served as the intervention, one session targeted the intentional use of caring activities; the second session focused on how to engage an ethic of care at the point of service. The two treatment sites, Site A and Site B, participated in each of the training sessions at two different times; Site $C$ served as a non-treatment condition and did not receive any study-specific staff training. Training sessions were scheduled approximately two weeks apart to allow time for the intervention to take effect. The first trainings took place following a baseline period just prior to the start of week 3 of the camp session. The second trainings took place between weeks 4 and 5 . Trainings were counter balanced to account for order effects and to compare the effects of the two different training approaches (Table 1).

Table 1

Intervention Timeline

\begin{tabular}{|cccc|}
\hline & & Session 1 & Session 2 \\
\cline { 2 - 4 } & Time 1: & Time 2: & Time 3: \\
& Baseline Phase & Treatment Phase 1 & Treatment Phase 2 \\
\hline Site A & No Treatment & Ethic of Care Training & Caring Activities Training \\
Site B & No Treatment & Caring Activities Training & Ethic of Care Training \\
Site C & No Treatment & Baseline Phase & Baseline Phase \\
\hline
\end{tabular}

Note: Youth completed questionnaires at the end of Time 1, 2, and 3, which aligned with program weeks 2, 4, and 6 respectively.

The questionnaire was administered at each site at three different times over the course of the summer: Time 1 (week 2 of the program), Time 2 (week 4), and Time 3 (week 6). Time 1 represented a baseline condition as neither sites had received the training intervention; Times 2 and 3 were selected to capture the effects of the two training sessions independently (Time 2) and in combination (Time 3). Independently, the trainings targeted program design and staff implementation respectively; the combined sessions represented the unified caring communities intervention. 
The first staff training session, Caring Activities Training, targeted program design factors. Program design factors included caring activities adapted from the Caring School Communities (CSC) curriculum (Battistich, et al., 1997). The one and a half hour training took place in the evening immediately following the program and was conducted by one of the authors at the program facility. The general structure of the training included an overview of each caring activity, practice implementing the activity, and discussion about how and when each activity would be included in the program schedule.

Staff were trained to deliver four specific caring activities. The first activity was a cross-age buddy activity designed to foster interpersonal connectedness among youth participants. The second activity was a team meeting that was used to foster behavioral norms for caring within small age-based groups. The third set of activities included caring-based team challenges designed to promote an overall sense of community in the small, age-based group. The fourth activity was a program-wide activity that was used to foster a sense of care for the community at large (Solomon, Watson, Battistich, Schaps, \& Delucchi, 1996).

The second training session, the Ethic of Care Training, targeted implementation factors. Staff implementation factors were defined to include the ways staff members engage an ethic of care at the point of service. This session was based on Noddings' (2003) conception of pedagogical caring, which includes four processes by which people adopt an ethic of care: modeling, practice, reflection, and confirmation. For modeling, the trainer role-played a caring exchange and staff discussed the elements of the exchange that were unique to caring. The trainer then facilitated dialogue about the differences between relational caring and justice-oriented caring. Discussion questions focused on when each approach is appropriate and why caring is critical for positive youth development. Each staff member practiced the caring exchange through an ethical scenario in which the primary actor faced a dilemma that involved caring for other people. Finally, the trainer facilitated a round of confirmation in which staff members shared their caring intentions for the upcoming sessions.

\section{Data Analysis}

Analysis of within- and between-subjects effects was used to examine potential differences between sites as well as changes in youths' sense of caring community over time. Qualitative data gathered from the staff interviews were analyzed by one of the authors using thematic reduction (Denzin, \& Lincoln, 2011). Interview data were inspected for themes related to staff members' implementation of caring activities and adoption of an ethic of care. Themes were then confirmed with interviewees to ensure accurate representation of their experience with the caring communities intervention.

\section{Results}

\section{Results of Quantitative Data}

Fifty-five youth between the ages of 7 and 14 years old completed the questionnaire all three times. Fifty-three percent of the participants were male $(N=32)$ and $42 \%$ were female $(N=$ 23). The average age was 10.8 years old. Table 2 outlines the means on the questionnaire at Time 1, Time 2, and Time 3 between the treatment group (Sites A and B combined) and nontreatment group (Site $\mathrm{C}$ ). The two facets of caring community, caring and connectedness, are reported here separately. 
For caring, analysis of variance between treatment and nontreatment groups revealed a significant time by treatment interaction $\left(F(2,106)=3.442, p<.05\right.$; partial $\left.\eta^{2}=.061\right)$. Table 2 depicts the complete results of the analysis of variance for caring.

Table 2

Average Scores on the Caring Community Questionnaire for Sites Receiving Staff Training and Comparison Site (with Standard Deviation in Parentheses)

\begin{tabular}{|c|c|c|c|c|c|c|}
\hline \multirow[b]{3}{*}{$\begin{array}{l}\text { Sites } \\
A \& B\end{array}$} & \multicolumn{2}{|c|}{ Time 1} & \multicolumn{2}{|c|}{ Time 2} & \multicolumn{2}{|c|}{ Time 3} \\
\hline & CCLS & CCOS & CCLS & ccos & CCLS & CCOS \\
\hline & $5.39(.567)$ & $5.03(.733)$ & $5.35(.728)^{1}$ & $4.91(.983)$ & $5.07(.827)$ & $4.76(.936)$ \\
\hline Site C & $5.09(.588)$ & $4.86(.644)$ & $4.88(.685)$ & $4.67(.914)$ & $5.03(.738)$ & $4.52(1.00)$ \\
\hline
\end{tabular}

Note $^{1}$ : Significant difference between treatment and non-treatment sites at Time $2(p>.05)$

The significant time by treatment interaction for caring necessitated a simple effects analysis. Results of this test revealed a significant difference between the two conditions only at Time 2 $(t=2.17, d f=52, p=.018)$. The significant difference between treatment and non-treatment groups at Time 2 suggested that Site $A$ and $B$ together had higher scores on caring than the comparison camp following the intervention at Time 2. However, findings at Time 3 did not show a sustained difference between the treatment and non-treatment groups.

Unlike caring, results for connectedness did not show significant differences between the treatment and non-treatment groups. Results of a polynomial contrast revealed, for connectedness, a significant and negative linear trend for time $(F(1,53)=7.483, p<.05)$; therefore, it was determined that both the treatment and non-treatment means for connectedness decreased over time.

To address the second research question, the means of the two treatment conditions independently were compared within the combined mean of both treatment conditions. The findings did not reveal significant differences between the two trainings independently when compared with the training sessions in combination.

\section{Results of Qualitative Data}

Follow-up interviews with the site coordinators and staff members revealed the caring activities were incorporated with minimal adaptations or omissions; however, there were unexpected factors which may have influenced the impact of the staff training interventions. Youth and staff members from the comparison site (Site C), for example, were forced to relocate their program early in the summer due to a large environmental disaster that negatively impacted the park where the facility was located. The two experimental sites (Sites A and B) described a difficult cohort of youth and a notable degree of staff burnout.

\section{Discussion}

The purpose of this study was to examine the effects of a two-part staff training intervention targeting program design and staff implementation on youths' sense of caring community within an OST program. Caring communities were defined to include two distinct yet overlapping constructs: caring youth-staff interactions and an overall climate of connectedness within the 
setting as a whole. Training staff to facilitate structured activities and to engage an ethic of care at the point of service are two mechanisms through which youth might experience caring community; the findings from this study indicate that these mechanisms might impact some, but not all, aspects of caring community.

The first research question asked if the staff training intervention, which included the combined effects of the Ethic of Care and the Caring Activities sessions, impacted youths' sense of caring community more so than traditional OST program activities. Notable among the findings specific to this question were differences between treatment and non-treatment sites on the caring aspect of the caring community variable. These differences were not found in the connectedness variable; nor were there notable differences between the two design- and implementation-focused training sessions. Therefore, the following discussion highlights the relation between the combined staff training intervention and caring youth-staff relationships within a caring community.

With respect to youth-staff relationships, youths' perceptions of caring depended on whether or not their program leaders received the staff training intervention. A significant difference between treatment and non-treatment conditions at Time 2 suggests that the first round of staff training sessions may have impacted youths' sense of caring. However, this difference did not result from an increase in caring at Time 2; rather, caring merely stayed level at the treatment sites and declined at the non-treatment site.

There are three potential explanations for the findings specific to the youth-staff relationships. First, it is possible that staff members receiving a specialized training implemented the activities with greater fidelity immediately following the training than in the weeks afterwards. It is also possible that the training might offset declines in caring that can occur over time. Finally, the one-time training might not have provided the dosage necessary to sustain an impact for the duration of the program. Previous studies suggest that staff training is a mechanism for promoting caring community (e.g., Battistich, et al., 2004; Newton, et al., 2007; Solomon, et al., 1996) and this study supports this notion, if only in part.

The decline in caring between Time 2 and Time 3, then, calls into question the durability of a staff training designed to promote caring community. In this study, the first program session ended and the second session began in between Time 2 and 3 . While the participants of this study attended both sessions of the OST program, there was a higher than expected turnover between the two sessions. Interestingly, Sites $A$ and $B$, which received each training session but in the opposite order, declined in a similar fashion, while Site C, which did not receive either of the training sessions, actually increased, albeit non-significantly, between Time 2 and Time 3 . One possible explanation for this trend is that the staff training did not effectively buffer Sites A and $B$ from the effects of challenging dynamics within the youth population and an overall sense of burnout among staff.

Post-intervention interviews revealed a relation between the staff training and a consistently disruptive youth cohort. Staff at treatment Site A, for example, reported that a large group of 12- and 13-year-old boys, most of whom had attended the program for several years, were particularly problematic, especially during the second session of the summer. In contrast, staff members from Site $\mathrm{C}$ indicated that the camper population was without notably disruptive cohorts; in fact, the group faced an unexpected event that, according to staff interviews, actually drew youth together and compelled them to function as a team throughout the summer. 
Groups of program participants that challenge norms and processes are a known barrier to staff effectiveness in youth programs (Larson, \& Walker, 2010), particularly when they go beyond staffs' expertise at the point of service (Larson, et al., 2009). Likewise, even robust, intentionally designed activities are prone to the influence of youth characteristics (Durlak, \& DuPre, 2008). OST programs with highly transient youth populations in particular often experience difficulty targeting and achieving positive youth development outcomes (Roth, \& Brooks-Gunn, 2003), especially if youth interactions are affected by complex social dynamics related to race (Moore, 2002) and gender (Moore, 2001). In general, the ways peer dynamics impact the extent to which a given staff training session achieves its intended outcomes are well documented (e.g., Durlak, Weissberg, \& Pechan, 2010; Grossman, \& Bulle, 2006).

In addition to the challenging youth cohorts, staff members from both treatment sites reported that staff member burnout negatively impacted program processes toward the end of the summer. Staff burnout is a major concern among OST practitioners, especially in programs that employ inexperienced emerging adults (Paisley, \& Powell, 2007). It is possible that young adults lack the emotional maturity to withstand the dynamic nature of the youth program environment, which, in some cases, becomes increasingly stressful as the summer unfolds (Larson, \& Walker, 2010). Emotional exhaustion may have caused burnout among program staff members, which, in this case, explains differences between the treatment and nontreatment sites.

It is also possible that caring, as it was conceptualized in this study, actually contributed to staff burnout. Noddings' (2003) care theory was the framework used here to predict the nature of caring between youth and staff; Noddings' (2003) concept of pedagogical caring served as the conceptual basis for the staff training interventions. While this study acknowledged the limitations young people might face in adopting an ethic of care, it was hypothesized that program participants could enter into a caring relation with their leaders without necessarily adopting an ethic of care of their own. According to Noddings (2003), ethical caring is not possible without a reciprocal exchange, meaning if a caring staff member does not receive care in some way, then the ethic of care is not confirmed. While Noddings does not speak explicitly to the emotional effects of an unmet extension of care, burnout, in the OST setting, is a plausible result.

In this study, OST staff participated in two trainings, one focused on program design factors and one on implementation factors, in order to assess their independent and combined effects on caring community. While no differences were found between the two training sessions, results indicate that the combined staff training may have offset the effects of negative peer cohorts and staff burnout. Declines in caring community over time are particularly interesting because they suggest staff training is promising but not necessarily sufficient mechanism to promote this multidimensional outcome.

\section{Limitations}

OST programs in general encompass an array of participant, staff, and program factors and the combination of these factors present many challenges to applied research in this setting.

Sample size was a limitation. Staff member absenteeism and reduced meeting time may have imposed additional limitations on the findings of this study. Site coordinators in the program used in this study do not normally hold formal meetings with their staff members throughout the program and, although staff members were paid to attend the training sessions for this study, their attendance was voluntary. 


\section{Implications for Practice}

OST programs may be uniquely situated to promote a sense of caring community, yet the ways in which program administrators train staff to foster caring community requires further attention. This study suggested that staff training may be an effective way to impact youths' sense of caring community but, despite this finding; it is possible that a training that focuses both program design and staff implementation does not sufficiently prepare staff to promote caring community in the OST environment. Staff training "booster sessions," or short, focused trainings that are conducted at regular intervals throughout the program session, may be one way program administrators might improve the durability of staff training sessions designed to promote caring community.

In addition to training durability, program administrators should also consider the extent to which OST staff can engage an ethic of care when interacting with youth at the point of service. While several scholars recommend OST staff are trained to respond to the dynamic nature of the OST context (e.g., Borden, et al., 2004; Larson, et al., 2009; Rhodes, 2004), this study demonstrated that training staff to engage an ethic of care has limitations. Little is known about effective staff training mechanisms in youth programs in general (Shek, \& Wai, 2008), yet OST programs increasingly rely on staff to promote a myriad youth development goals (Borden, Schlomer, \& Wiggs, 2004). Practitioners should make provisions for staff members' developmental readiness to adopt an ethic of care or other areas of "expertise" that might improve staff-youth interactions at the point of service.

It is also worth considering mechanisms other than staff training, such as youth-centered initiatives, that might support the development of caring communities in OST settings. Engaging youth in meaningful decision making within the OST context is an emerging area of interest among professionals. Weiss, Little, and Bouffard (2005), for example, describe engagement as a key process by which youth participants gain the intended outcomes of the program. Practitioners interested in promoting caring community might consider ways to give youth participants the skills necessary to actively form supportive relationships with staff and with their peers.

Professionals and scholars alike should keep in mind that the techniques and processes related to OST staff training are rich in opportunities for future research. While it is generally accepted that program staff members are critical to youths' experience in OST programs, this study suggests that staff members may be limited in their attempts to foster an overall sense of caring community among youth. Research partnerships between scholars and professionals might provide critical insight into the processes for training staff to foster a caring community.

\section{References}

American Camp Association (2011). Camp Youth Outcomes Battery ( $2^{\text {nd }}$ ed.). Martinsville, IN: American Camp Association.

Battistich, V., Schaps, E., \& Wilson, N. (2004). Effects of an elementary school intervention on students' "connectedness" to school and social adjustment during middle school. Journal of Primary Prevention, 24, 243-262. 
Battistich, V., Solomon, D., Watson, M., \& Schaps, E. (1997). Caring school communities. Educational Psychologist, 32, 137-151.

Bialeschki, M.D., Henderson, K.A., \& James, P.A. (2007). Camp experiences and developmental outcomes for youth. Child \& Adolescent Psychiatric Clinics of North America, 16, 769-788.

Borden, L.M., Schlomer, G.L., \& Wiggs, C.B. (2004). The evolving role of youth workers. Journal of Youth Development, 6(3), 126-138.

Catalano, R.F., Berglund, M.L., Ryan, J.A., Lonczak, J., \& Hawkins, D. (2004). Positive youth development in the United States: Research findings on evaluations of positive youth development programs. Annals of the American Academy of Political and Social Science, 591, 98-124.

Denzin, N.K., \& Lincoln, Y.S. (2011). The SAGE Handbook of qualitative research (4th ed.). Los Angeles: Sage Publications.

Domitrovich, C.E., \& Greenberg, M.T. (2000). The study of implementation: Current findings from effective programs that prevent mental disorders in school-aged children. Journal of Educational and Psychological Consultation, 11(2), 193-221.

Durlak, J.A., \& DuPre, E.P. (2008). Implementation matters: A review of the research on the influence of implementation on program outcomes and the factors affecting implementation. American Journal of Community Psychology, 41, 327-350.

Durlak, J.A., Weissberg, R.P., \& Pachan, M. (2010). A meta-analysis of after-school programs that seek to promote personal and social skills in children and adolescents. American Journal of Community Psychology, 45, 294-309.

Eccles, J., \& Gootman, J. A. (2002). Community programs to promote youth development. Washington, D.C.: National Academies Press.

Ellis, G.D., \& Rossman, J.R. (2008). Creating value for participants through experience staging: Parks, recreation, and tourism in the experience industry. Journal of Park and Recreation Administration, 26(4), 1-20.

Ewert, A., \& Sibthorp, J. (2014). Outdoor Adventure Education: Foundations, Theory, and Research. Human Kinetics, Champaign IL.

Garst, B., Browne, L.P., \& Bialeschki, M.D. (2011). Youth development and the camp experience. New Directions for Youth Development, 130, 73-87.

Grossman, J.B., \& Bulle, M.J. (2006). Review of what youth programs do to increase the connectedness of youth and adults. Journal of Adolescent Health, 39, 788-799.

Halpern, R., Barker, G., \& Mollard, W. (2000). Youth programs as alternative spaces to be: A study of neighborhood youth programs in Chicago's West Town. Youth \& Society, 31, 469-506.

Larson, R.W., \& Walker, K.C. (2010). Dilemmas of practice: Challenges to program quality encountered by youth program leaders. American Journal of Community Psychology, 45, 338349. 
Larson, R.W., Rickman, A.N., Gibbons, C.M., \& Walker, K.C. (2009). Practitioner expertise: Creating quality within the daily tumble of events in youth settings. New Directions for Youth Development, 121, 71-88.

Libbey, H.P. (2004). Measuring student relationships to school: Attachment, bonding, connectedness, and engagement. Journal of School Health, 74, 274-283.

McNeely, C., \& Falci, C. (2004). School connectedness and the transition into and out of health-risk behavior among adolescents: A comparison of social belonging and teacher support. Journal of School Health, 74(7), 285-292.

Moore, V.A. (2001). "Doing" racialized and gendered age to organize peer relations: Observing kids in summer camp. Gender \& Society, 15(6), 835-858.

Moore, V.A. (2002). The collaborative emergence of race in children's play: A case study of two summer camps. Social Problems, $49(1), 58-78$.

Newton, M., Watson, D.L., Gano-Overway, L., Fry, M., Kim, M., \& Magyar, M. (2007). The role of a caring-based intervention in a physical activity setting. The Urban Review, 39, 281-299.

Newton, M., Fry, M., Watson, D., Gano-Overway, L., Kim, M., Magyar, M., \& Guivernau, M. (2009). Psychometric properties of the Caring Climate Scale in a physical activity setting. Revista de Psicología del Deporte, 16(1), 67-84.

Noddings, N. (2003). Caring: A feminine approach to ethics and moral education ( $2^{\text {nd }}$ ed.). Berkeley, CA: University of California Press.

Paisley, K., \& Powell, G.M. (2007). Staff burn-out prevention and stress management. Child \& Adolescent Psychiatric Clinics of North America, 16, 829-841.

Resnick, M.D., Bearman, P.S., Blum, R. W., et al. (1997). Protecting adolescents from harm: Findings from the National Longitudinal Study on Adolescent Health. Journal of the American Medical Association, 278, 823-832.

Rhodes, J.E. (2004). The critical ingredient: Caring youth-staff relationships in after-school settings. New Directions for Youth Development, 101, 145-161.

Rice, M., Kang, D., Weaver, M., \& Howell, C.C. (2008). Relationship of anger, stress, and coping with school connectedness in fourth-grade children. Journal of School Health, 78(3), 149-156.

Roark, M.F., Gillard, A., Evans, F., Wells, M.S., \& Blauer, M.M. (2012). Effect of intentionally designed experiences on friendship skills of youth: An application or symbolic interaction theory. Journal of Park and Recreation Administration, 30(3), 24-36.

Roth, J.L., \& Brooks-Gunn, J. (2003). Youth development programs: Risk, prevention, \& policy. Journal of Adolescent Health, 32, 170-182.

Shek, D.T.T., \& Wai, C.L.Y. (2008). Training workers implementing adolescent prevention and positive youth development programs: What have we learned from the literature? Adolescence 43(73), 823-845. 
Shochet, I.M., Dadds, M.R., Ham, D., \& Montague, R. (2006). School connectedness is an underemphasized parameter in adolescent mental health: Results of a community prediction study. Journal of Clinical Child and Adolescent Psychology, 35(2), 170-179.

Smith, C., Devaney, T.J., Akiva, T., \& Sugar, S.A. (2009). Quality and accountability in the outof-school-time sector. New Directions for Youth Development, 121, 109-127.

Solomon, D., Watson, M., Battistich, V., Schaps, E., \& Delucchi, K. (1996). Creating classrooms that students experience as communities. American Journal of Community Psychology, 24, 719748.

Tarlow, B. (1996). Caring: A negotiated process that varies. In S. Gordon, P. Benner, \& N. Noddings (Eds.). Caregiving: Readings in knowledge, practice, ethics, and politics (pp. 56-82). Philadelphia, PA: University of Pennsylvania.

Thurber, C.A., Scanlin, M.M., Scheuler, L., \& Henderson, K.A. (2007). Youth development outcomes of the camp experience: Evidence for multidimensional growth. Journal of Youth \& Adolescence, 36, 241-254.

Weiss, H.B., Little, P.M.D., \& Bouffard, S.M. (2005). More than just being there: Balancing the participation equation. New Directions for Youth Development, 105, 15-31.

(C) Copyright of Journal of Youth Development Bridging Research and Practice. Content may not be copied or emailed to multiple sites or posted to a listserv without copyright holder's express written permission. Contact Editor at: patricia.dawson@oregonstate.edu for details. However, users may print, download or email articles for individual use.

ISSN 2325-4009 (Print); ISSN 2325-4017 (Online) 